\title{
Does dehydration prior to primary total joint arthroplasty increase risk of perioperative complications?
}

\author{
Harold G. Moore', Marissa A. Justen², David S. Kirwin², Patrick J. Burroughs², Lee E. Rubin ${ }^{3}$ and \\ Jonathan N. Grauer ${ }^{3 *}$ (D)
}

\begin{abstract}
Background: Prior studies have suggested that preoperative dehydration increases odds of perioperative complications in several areas of orthopedic surgery. This study aimed to evaluate whether preoperative hydration status is associated with the incidence of short-term complications after primary total joint arthroplasty.

Methods: The 2012-2019 National Surgical Quality Improvement Program (NSQIP) database was used to explore the relationship between preoperative dehydration (ratio of preoperative BUN divided by preoperative Creatinine (BUN/ Creatinine) > 20) and perioperative outcomes of total hip (THA) and total knee arthroplasty (TKA) patients. Univariate comparisons and multivariate regression analyses were conducted to identify specific complications that occurred more often in patients with preoperative dehydration.

Results: Of 188,629 THA and 332,485 TKA patients, 46.3 and $47.0 \%$ had preoperative dehydration, respectively. After controlling for demographics and comorbidities, dehydrated THA patients were no more likely to experience a complication compared to their non-dehydrated counterparts (relative risk $[R R]=0.97,99.7 \%$ Confidence Interval $[\mathrm{Cl}]: 0.92-1.03, P=0.138)$ nor increased risk of blood transfusion $(\mathrm{RR}=1.02, \mathrm{Cl}=0.96-1.08, P=0.408)$. Similar to THA patients, dehydrated TKA patients were not more likely to have a complication after surgery $(\mathrm{RR}=0.97, \mathrm{Cl}=0.92-1.03$, $P=0.138)$ and were at no greater risk of transfusion $(R R=1.02, C l=0.96-1.07, P=0.408)$. A sub-analysis covering only patients with BUN and $\mathrm{Cr}$ values determined within $24 \mathrm{~h}$ after surgery was performed and similarly found no significant increase in perioperative complications or transfusion.
\end{abstract}

Conclusion: Overall, preoperative dehydration in patients undergoing THA/TKA did not appear to increase risk of transfusion or other perioperative complications. Further research is needed to characterize the role of hydration prior to elective total joint arthroplasty.

Keywords: Total knee arthroplasty, Total hip arthroplasty, Dehydration, Hydration, Transfusion

\section{Introduction}

There is an increasing emphasis in total joint arthroplasty on optimizing the patient prior to surgery to reduce risk of postoperative complications and expedite recovery.

\footnotetext{
*Correspondence: jonathan.grauer@yale.edu

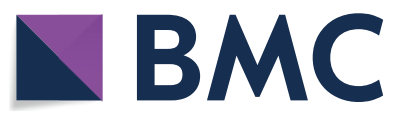

${ }^{3}$ Department of Orthopaedics and Rehabilitation, Yale School of Medicine, 47 College Street, New Haven, CT 06511, USA

Full list of author information is available at the end of the article
Attention is often paid to exercise tolerance [1], optimizing management of medical comorbidities, and performing routine laboratory testing to ensure there are no gross electrolyte [2], nutritional [3], or hematologic abnormalities $[4,5]$. One factor that has garnered increased attention in several areas of orthopedics is preoperative hydration status [6]. (c) The Author(s) 2021. Open Access This article is licensed under a Creative Commons Attribution 4.0 International License, which permits use, sharing, adaptation, distribution and reproduction in any medium or format, as long as you give appropriate credit to the original author(s) and the source, provide a link to the Creative Commons licence, and indicate if changes were made. The images or other third party material in this article are included in the article's Creative Commons licence, unless indicated otherwise in a credit line to the material. If material is not included in the article's Creative Commons licence and your intended use is not permitted by statutory regulation or exceeds the permitted use, you will need to obtain permission directly from the copyright holder. To view a copy of this licence, visit http://creativecommons.org/licenses/by/4.0/. The Creative Commons Public Domain Dedication waiver (http://creativeco mmons.org/publicdomain/zero/1.0/) applies to the data made available in this article, unless otherwise stated in a credit line to the data. 
Patients are often dehydrated prior to surgery and can require fluid not only to replace intraoperative and postoperative fluid losses but also to assist in replenishing fluid deficits present prior to surgery. Nausea and vomiting are frequent side effects of the postoperative narcotic regimen [7] and can result in further fluid loss, and patients are often restricted in their oral intake prior to surgery for anesthetic safety similar to how patient intake is restricted prior to drawing blood for routine laboratory tests [8]. Several studies examining the role of oral and intravenous preoperative hydration found that such protocols improved postoperative recovery with less nausea and vomiting $[9,10]$.

Hydration status can be inferred in a number of ways, including clinical signs such as skin turgor, flattening of neck veins, and more quantifiable blood pressure, heart rate, and urine specific gravity [11]. Another widely adopted metric for assessing hydration status is the Blood Urea Nitrogen (BUN)/Creatinine $(\mathrm{Cr})$ ratio. In the literature, thresholds for the dehydrated state range from a ratio greater than 15 to a ratio greater than 25 , but the threshold is most commonly set at a ratio greater than 20 $[12,13]$. However, the relationship between preoperative hydration status and postoperative complications in total joint arthroplasty is largely unexplored.

Total joint arthroplasty is one of the most common orthopedic procedures performed in the United States and is increasing in frequency every year as the population ages, with the combined volume of primary total hip and total hip procedures expected to approach 2 million annually by 2030 [14]. Given the susceptibility of elder patients to changes in hydration status and the high prevalence of dehydration in this age group [15], the authors hypothesized that preoperative hydration status in TJA may increase the risk of complications within the perioperative period, including transfusion, infection, acute kidney injury, and hospital readmission [16].

For the current study, a large national surgical database was used to examine whether preoperative patient hydration status, as defined by $\mathrm{BUN} / \mathrm{Cr}$ ratio, is associated with increased incidence of 30-day postoperative complications.

\section{Materials and methods}

\section{Data source}

The American College of Surgeon's NSQIP Database is a prospective, risk-adjusted database administered by the American College of Surgeons that collects data on patient demographics and comorbidities, perioperative characteristics and postoperative complications through the $30^{\text {th }}$ postoperative day regardless of discharge destination for over 700 participating institutions in the United States. Clinical reviewers employed by each participating hospital gather data directly from patient charts and input data into the database, and data are regularly audited for accuracy. Our institutional review board has granted exemption to studies using this deidentified database.

\section{Patient population}

Patients undergoing elective total hip arthroplasty (THA) and total knee arthroplasty (TKA) from the years 2012 to 2019 were identified using the Current Procedural Terminology (CPT) Code 27477 and 27130, respectively. Only those patients with complete data for all preoperative and postoperative variables were included. Patients who underwent surgery for diagnoses other than osteoarthritis (such as for infections, neoplasia, or revision as identified by their International Classification of Disease code) were also excluded from the study. Patients with chronic renal failure or who were on dialysis prior to surgery were also excluded because BUN and creatinine levels were elevated and were a poor indicator of hydration status in these populations [17]. Figure 1 illustrates how the ultimate study population was determined.

Preoperative characteristics were obtained directly from NSQIP and included age, sex, height, weight, functional status, American Society of Anesthesiologists (ASA) score, diabetes status, smoking status, and congestive heart failure (CHF). Body mass index (BMI) was calculated using height and weight data $\left(\mathrm{kg} / \mathrm{m}^{2}\right)$, which are chart-abstracted and can be either objective measures or self-reported measures, depending on the practice of individual NSQIP member institutions. ASA class was used as a simplified measure of patient comorbidity status and has been demonstrated to correlate strongly with other comorbidity indices $[18,19]$.

\section{Perioperative complications}

NSQIP follows up individual complications in 30-day postoperative period, regardless of discharge destination. The individual complications included transfusion, death, urinary tract infection (UTI), pneumonia, return to OR, wound-related complications, thromboembolic events, sepsis and septic shock, cardiac complications, renal complications, and cerebrovascular accident. In the current study, pulmonary embolism and deep vein thrombosis were categorized as "thromboembolic events," while superficial surgical site infection, deep wound infection, wound dehiscence, and organ space infection were categorized as "wound-related complications." Blood transfusion was noted if blood was given during surgery or within the first $72 \mathrm{~h}$ postoperatively.

Postoperative length of stay (LOS) and readmission were also directly reported in the NSQIP database. LOS is defined as the number of days from the operation date 


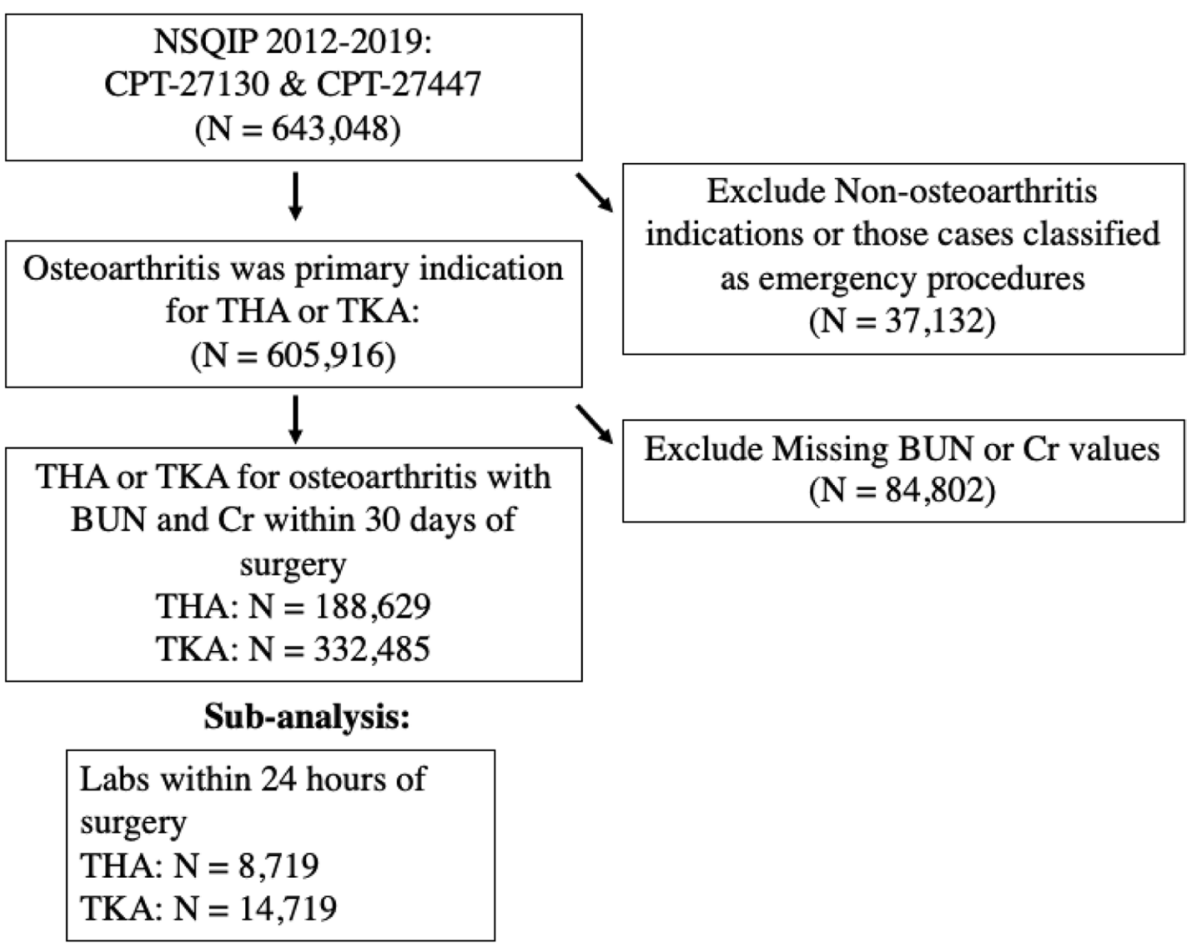

Fig. 1 Flow diagram representing arrival at overall patient population as well as the population used for supplemental sub-analysis of those patients with BUN and creatinine labs drawn within $24 \mathrm{~h}$ of surgery

until discharge (with maximum of 30 days). Extended LOS was defined as any LOS greater than 1 standard deviation above the mean for all cases ( 3 days for both THA and TKA). Readmission was noted if there was an admission for any reason occurring within the 30-day postoperative period.

In the NSQIP database, the laboratory values and the date the laboratory values were drawn are recorded. The blood BUN and $\mathrm{Cr}$ values were always recorded on the same date as both are drawn together as part of the basic metabolic panel. BUN/Cr values in NSQIP were recorded closest to surgery with no limit to the number of days prior to surgery that most recent value was recorded. A sub-analysis was additionally performed specifically examining patients within 24 and $72 \mathrm{~h}$ prior to surgery to evaluate possible bias between time and surgery and laboratory draws (Supplemental Tables 1, 2, 3 and 4).

\section{Statistical analysis}

All statistical analyses were completed using Stata version 15 . To begin with, patients who underwent THA and TKA were divided into two categories: $\mathrm{BUN} / \mathrm{Cr} \leq 20$ and $\mathrm{BUN} / \mathrm{Cr}>20$. Preoperative demographics and comorbidities between the 2 groups were compared in a univariate fashion using Chi-Squared test with significance set at $P<0.05$.

Next, multivariate Poisson regression with robust error variance was used to compare the relative risk of adverse outcomes that occurred within the 30-day postoperative period. Multivariate regressions were controlled for preoperative characteristics that were found to be significant in the univariate comparisons. Because 15 outcomes were examined, Bonferroni's correction was used to denote significance at $P<0.003$. Accordingly, $99.7 \%$ confidence intervals were reported.

\section{Results}

Total hip arthroplasty cohorts

A total of 188,629 THA patients met inclusion/exclusion criteria. Of these patients, $87,337(46.3 \%)$ were dehydrated based on preoperative laboratory studies. These patients who fit the definition for having preoperative dehydration were: older, more likely to be female, have lower BMI, have a preoperative dependent functional status, have a higher ASA, have diabetes, and have congestive heart failure (CHF). Of note, those patients that met the criteria for dehydration had a lower prevalence of tobacco use (Table 1 ). When only those patients with BUN and $\mathrm{Cr}$ values within $24 \mathrm{~h}$ of surgery were evaluated, they had similar findings but 
Table 1 Demographics and comorbidities for patients undergoing primary total hip arthroplasty

\begin{tabular}{|c|c|c|c|c|c|}
\hline \multirow[t]{3}{*}{ Demographics and Comorbidities } & \multicolumn{4}{|c|}{ Hydration Status } & \multirow[t]{3}{*}{$P^{\mathrm{a}}$} \\
\hline & \multicolumn{2}{|c|}{ Non-Dehydrated } & \multicolumn{2}{|l|}{ Dehydrated } & \\
\hline & $n=101,292$ & & $n=87,337$ & & \\
\hline Age (years) mean $\pm S D$ & $63.9 \pm 11.0$ & & $67.7 \pm 10.2$ & & $<0.001$ \\
\hline Gender & & & & & $<0.001$ \\
\hline Female & 45,210 & $44.6 \%$ & 58,657 & $67.2 \%$ & \\
\hline $\mathrm{BMI}\left(\mathrm{kg} / \mathrm{m}^{2}\right)$ & & & & & $<0.001$ \\
\hline$<18$ & 333 & $0.3 \%$ & 492 & $0.6 \%$ & \\
\hline $18-25$ & 16,522 & $16.3 \%$ & 17,773 & $20.4 \%$ & \\
\hline $25-30$ & 34,058 & $33.6 \%$ & 28,490 & $32.6 \%$ & \\
\hline $30-35$ & 28,208 & $27.9 \%$ & 21,806 & $25.0 \%$ & \\
\hline $35-40$ & 14,546 & $14.4 \%$ & 12,053 & $13.8 \%$ & \\
\hline$>40$ & 7625 & $7.5 \%$ & 6723 & $7.7 \%$ & \\
\hline Functional status prior to surgery & & & & & $<0.001$ \\
\hline Independent & 99,871 & $98.6 \%$ & 85.864 & $98.3 \%$ & \\
\hline Dependent & 1421 & $1.4 \%$ & 1473 & $1.7 \%$ & \\
\hline ASA & & & & & $<0.001$ \\
\hline 1 & 3775 & $3.7 \%$ & 2822 & $3.2 \%$ & \\
\hline 2 & 53,429 & $52.8 \%$ & 46,766 & $53.6 \%$ & \\
\hline 3 & 42,353 & $41.8 \%$ & 36,260 & $41.5 \%$ & \\
\hline$\geq 4$ & 1735 & $1.7 \%$ & 1489 & $1.7 \%$ & \\
\hline Diabetes mellitus & & & & & $<0.001$ \\
\hline No diabetes mellitus & 89,009 & $87.8 \%$ & 76,018 & $87.0 \%$ & \\
\hline Non-insulin-dependent diabetes mellitus & 9488 & $9.4 \%$ & 8758 & $10.0 \%$ & \\
\hline Insulin-dependent diabetes mellitus & 2795 & $2.8 \%$ & 2561 & $3.0 \%$ & \\
\hline Smoker & & & & & $<0.001$ \\
\hline No & 86,850 & $85.7 \%$ & 79,577 & $91.1 \%$ & \\
\hline Yes & 14,442 & $14.3 \%$ & 7760 & $8.9 \%$ & \\
\hline Congestive heart failure & & & & & 0.007 \\
\hline No & 100,996 & $99.7 \%$ & 87,020 & $99.6 \%$ & \\
\hline Yes & 296 & $0.3 \%$ & 317 & $0.4 \%$ & \\
\hline
\end{tabular}

Bold fonts indicate statistical significance

${ }^{\text {a }}$ Statistical significance set at $P<0.05$

did not have increased prevalence of dependent functional status or CHF (Supplemental Table 1).

On multivariate analysis, dehydrated patients undergoing THA were not more likely to have a complication (relative risk $[R R]=0.96,99.7 \%$ confidence interval $[\mathrm{CI}]: 0.89-1.04, P=0.135)$ and did not have an increased postoperative requirement for blood transfusion, $(\mathrm{RR}=1.02, \mathrm{CI}: 0.96-1.08, P=0.408)$ (Table 2, Fig. 1). Similarly, the sub-analysis of patients having laboratory tests within $24 \mathrm{~h}$ of surgery also showed that no increased risk of complications was observed (Supplemental Table 2). However, the risk of readmission within 30 days of surgery was significantly lower $(\mathrm{RR}=0.92, \mathrm{CI}=0.85-0.99, P=0.001)$, with the absolute readmission rate being roughly $3 \%$ in both cohorts.

\section{Total knee arthroplasty cohorts}

A total of 332,485 TKA patients met inclusion/exclusion criteria. Of these patients, 156,113 (47.0\%) were dehydrated based on preoperative laboratory studies. These patients who fit the definition for having preoperative dehydration were: older, more likely to be female, have lower BMI, higher ASA, be diabetic, and less likely to smoke (Table 3, Fig. 2). The dehydrated TKA patients were similar with respect to functional status and CHF. In the stricter sub-analysis of BUN/Creatinine values drawn within $24 \mathrm{~h}$ of surgery, the same similarities and differences in demographic and comorbidity factors were evident (Supplemental Table 3).

Like THA patients, dehydrated TKA patients were not more likely to have a complication after surgery $(\mathrm{RR}=0.97, \mathrm{CI}: 0.92-1.03, P=0.138)$. Dehydrated TKA 
Table 2 Relative risk of complications in the 30-day postoperative period for patients undergoing primary total hip arthroplasty

\begin{tabular}{|c|c|c|c|}
\hline Total & $\mathrm{RR}^{\mathrm{a}}$ & $99.7 \% \mathrm{Cl}$ & $P^{\mathrm{b}}$ \\
\hline Any Complication & 0.96 & $0.89-1.04$ & 0.135 \\
\hline Extended length of stay ( $>3$ days) & 0.98 & $0.94-1.02$ & 0.164 \\
\hline Blood transfusion & 1.02 & $0.96-1.08$ & 0.408 \\
\hline Readmission & 0.92 & $0.85-0.99$ & 0.001 \\
\hline Death & 0.90 & $0.60-1.35$ & 0.437 \\
\hline Urinary tract infection & 1.00 & $0.86-1.17$ & 0.970 \\
\hline Pneumonia & 0.81 & $0.62-1.06$ & 0.021 \\
\hline Return to the operating room & 0.98 & $0.88-1.08$ & 0.507 \\
\hline Wound complications & 0.95 & $0.83-1.09$ & 0.269 \\
\hline Thromboembolic complications ${ }^{c}$ & 0.94 & $0.77-1.13$ & 0.303 \\
\hline Sepsis/septic shock & 0.88 & $0.66-1.17$ & 0.189 \\
\hline Respiratory complications & 0.76 & $0.52-1.12$ & 0.035 \\
\hline Cardiac complications & 1.06 & $0.81-1.38$ & 0.527 \\
\hline Renal complications & 0.80 & $0.53-1.21$ & 0.110 \\
\hline Cerebrovascular accident & 0.85 & $0.54-1.34$ & 0.293 \\
\hline
\end{tabular}

a Poisson regressions with robust error variance were used to compare these variables. Adjusted for age, gender, BMI, functional status, ASA class, diabetes, smoking status, and congestive heart failure

${ }^{\mathrm{b}}$ Bold fonts indicate statistical significance (significant at $P<0.003$ due to Bonferroni correction for multiple comparisons). $R R$ Relative risk, $\mathrm{Cl}$ Confidence interval ( $99.7 \% \mathrm{Cl}$ due to Bonferroni)

'Includes deep vein thrombosis and pulmonary embolism

patients did not experience increased risk of perioperative blood transfusion either $(\mathrm{RR}=1.02, \mathrm{CI}$ : 0.96-1.07, $P<0.001)$. Most other complications did not have an increased risk of complications (Table 4, Fig. 3). Lastly, as found in THA patients, TKA patients who met laboratory criteria for dehydration had significantly reduced risk of readmission ( $\mathrm{RR}=0.91, \mathrm{CI}$ : $0.86-0.97, P=<0.001$ ), or extended length of stay $(\mathrm{RR}=0.94, \mathrm{CI}$ : 0.91-0.97, $P=<0.001)$. In the sub-analysis, no significant increase in complications was noted (Supplemental Table 4).

\section{Discussion}

Optimizing patients prior to elective primary total joint arthroplasty is key to ensuring rapid postoperative recovery. While much attention has been directed toward medical management of recognized comorbid conditions, only recently has more attention been given to preoperative hydration status. The current study aimed to examine the association between preoperative dehydration and postoperative outcomes after THA and TKA.

Dehydration has long been established as a factor in recovery after several orthopedic surgeries [20, 21]. One small prospective study of 45 patients undergoing surgery for hip fracture used urine specific gravity upon arrival to the operating theater to quantify preoperative dehydration and found a quadrupled postoperative complication rate in the dehydrated group [22]. Another small study looking at only patients over 65 undergoing several different types of orthopedic surgery found similar results, including increased rates of readmission and overall mortality at 30 days [2].

In general, the association of preoperative hydration status with specific preoperative outcomes of THA and TKA have largely been unexamined. However, the role of hydration status in orthopedic surgical outcomes was more broadly assessed by both Ylinenvaara et al. and Chan et al. [12, 22]. Ylinenvaara et al. demonstrated that patients who were dehydrated were four times at the risk of experiencing an adverse postoperative outcome, and, more specifically, were more likely to have confusion, arterial desaturation and cardiovascular events. These conclusions were not supported by our findings. Chan et al., after examining the records of 216 patients, concluded that patients who had preoperative dehydration status were more likely to experience hematologic or gastrointestinal postoperative complications which is consistent with our finding of increased need for blood transfusion in both THA and TKA patients who were dehydrated prior to surgery [12]. The main difference between our study and the studies previously mentioned is that previous studies examined orthopedic surgeries more broadly, rather than patients specifically undergoing elective THA and TKA. Moreover, the mean age of study populations in Chan et al. [12] (81 years), and Ylinevaara et al. [22] (78 years), was not accounted for using multivariate analysis as it was in the present study. Accordingly, age and procedure type could have contributed to the differences these studies observed.

Based on univariate analyses, the current study found that both THA and TKA patients with preoperative dehydration were older, mostly female, and had a higher medical comorbidity burden than non-dehydrated patients. The above-noted findings align with previous literature that has demonstrated that dehydrated patients were, on average, older and more likely to be female than non-dehydrated patients [23]. Interestingly, those patients who were smokers were disproportionately more represented in the non-dehydrated group, a finding that may be partly explained by observations of altered creatine clearance in smokers [24, 25]. Based on multivariate analyses, the current study found that patients with preoperative dehydration undergoing both THA and TKA experienced reduced risk of postoperative complications within 30 days of surgery. For TKA in particular, they had slightly but significantly reduced risk of extended length of stay and were not more likely to require a blood transfusion. While the adjusted increase in relative risk was small, with large and increasing volume of THAs and 
Table 3 Demographics and comorbidities for patients undergoing primary total knee arthroplasty

\begin{tabular}{|c|c|c|c|c|c|}
\hline \multirow[t]{3}{*}{ Demographics and Comorbidities } & \multicolumn{4}{|c|}{ Hydration Status } & \multirow[t]{3}{*}{$P$-value ${ }^{a}$} \\
\hline & \multicolumn{2}{|c|}{ Non-Dehydrated } & \multicolumn{2}{|l|}{ Dehydrated } & \\
\hline & $N=176,372$ & & $N=156,113$ & & \\
\hline Age (years) mean $\pm S D$ & $65.9 \pm 9.5$ & & $68.2 \pm 9.0$ & & $<0.001$ \\
\hline Sex & & & & & $<0.001$ \\
\hline Female & 14,309 & $8.1 \%$ & 16,015 & $10.3 \%$ & \\
\hline BMI $\left(\mathrm{kg} / \mathrm{m}^{2}\right)$ & & & & & $<0.001$ \\
\hline$<18$ & 181 & $0.1 \%$ & 221 & $0.1 \%$ & \\
\hline $18-25$ & 14,309 & $8.1 \%$ & 16.015 & $10.3 \%$ & \\
\hline $25-30$ & 47,112 & $26.7 \%$ & 41,306 & $26.5 \%$ & \\
\hline $30-35$ & 52,210 & $29.8 \%$ & 44,598 & $28.6 \%$ & \\
\hline $35-40$ & 25,971 & $20.4 \%$ & 30,836 & $19.8 \%$ & \\
\hline$>40$ & 26,289 & $14.9 \%$ & 23,137 & $14.8 \%$ & \\
\hline Functional status prior to surgery & & & & & 0.528 \\
\hline Independent & 174,574 & $99.9 \%$ & 154,487 & $99.0 \%$ & \\
\hline Dependent & 1798 & $1.0 \%$ & 1626 & $1.0 \%$ & \\
\hline ASA & & & & & $<0.001$ \\
\hline 1 & 3030 & $1.7 \%$ & 2547 & $1.6 \%$ & \\
\hline 2 & 82,401 & $46.7 \%$ & 76,620 & $49.1 \%$ & \\
\hline 3 & 87,695 & $49.7 \%$ & 74,604 & $47.8 \%$ & \\
\hline$\geq 4$ & 3246 & $1.8 \%$ & 2342 & $1.5 \%$ & \\
\hline Diabetes mellitus & & & & & 0.032 \\
\hline No diabetes mellitus & 143,737 & $81.5 \%$ & 127,171 & $81.5 \%$ & \\
\hline Non-insulin-dependent diabetes mellitus & 24,634 & $14.0 \%$ & 22,107 & $14.0 \%$ & \\
\hline Insulin-dependent diabetes mellitus & 8001 & $4.5 \%$ & 6835 & $4.4 \%$ & \\
\hline Smoker & & & & & $<0.001$ \\
\hline No & 158,498 & $89.9 \%$ & 147,051 & $94.2 \%$ & \\
\hline Yes & 17,874 & $10.1 \%$ & 9062 & $5.8 \%$ & \\
\hline Congestive heart failure & & & & & 0.707 \\
\hline No & 175,794 & $99.7 \%$ & 155,613 & $99.7 \%$ & \\
\hline Yes & 578 & $0.3 \%$ & 500 & $0.3 \%$ & \\
\hline
\end{tabular}

Bold fonts indicate statistical significance.

${ }^{\text {a }}$ Statistical significance set at $P<0.05$

TKAs being performed globally [26], this small difference at scale can be clinically significant.

For TKA and THA patients, the current study found that preoperative dehydration did not result in an appreciable elevation in the risk of complications. Of note, the sub-analysis conducted for patients within $24 \mathrm{~h}$ of surgery had a less statistical power and did not find any significant increase in complications, as patients undergoing laboratory testing within $24 \mathrm{~h}$ of surgery comprised only $4.5 \%$ of the overall study population. This should be taken into account when considering the generalizability of the results of the sub-analysis and highlights the need to conduct more regimented studies drawn at pre-defined intervals prior to surgery.
Recently, novel multi-modal approaches have been developed to try to reduce transfusions after total joint arthroplasty by optimizing preoperative hemoglobin, reducing perioperative blood loss, and imposing strict transfusion requirements. In one study of 1010 patients, the transfusion rate was reduced from 18 to $1.4 \%$ by applying these measures in addition to optimizing hydration prior to surgery [27]. In our study population, the transfusion rate was 5.6 and $3.4 \%$ in THA and TKA respectively, suggesting that further reduction is possible. One factor that might explain the high transfusion rates compared to contemporary rates is use of tranexamic acid (TXA). TXA's use was not popularized in total joint arthroplasty in the most of the years of the study but is 


\section{Multivariate Odds of Complications after THA}

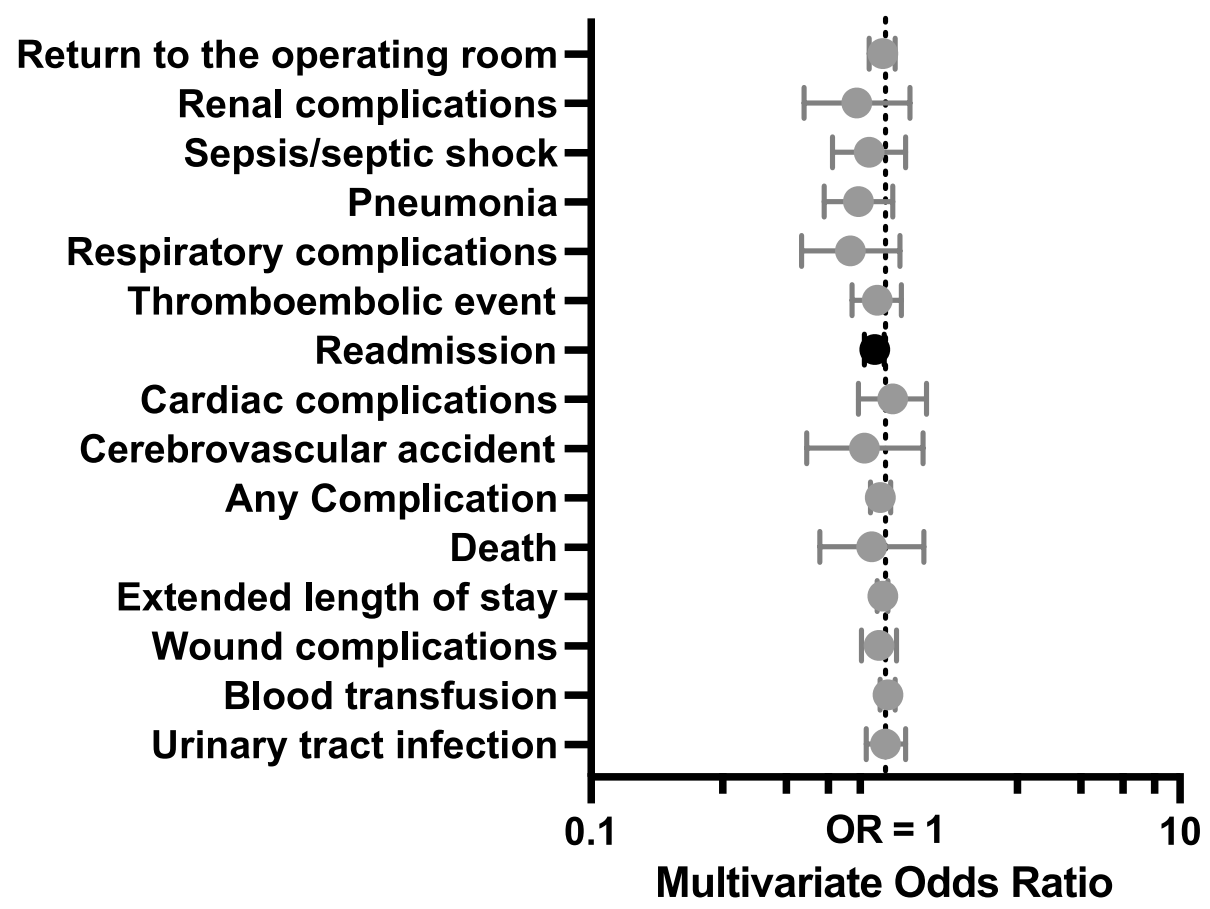

Fig. 2 Relative risk of complications that occurred anytime during the 30-day postoperative period following total hip arthroplasty in non-dehydrated vs. dehydrated patients. Dark shading indicates statistical significance

likely represented to a more appreciable degree during the last several years in the study [28].

More specific to total joint arthroplasties, a study by Mukand et al. [29] in 2003 examined the effects of dehydration on in-patient rehabilitation of patients who underwent THA, TKA, or had a hip fracture by using orthostasis and azotemia as metrics of dehydration. However, they found that, contrary to the present study, dehydrated patients were at a higher risk of having an extended length of hospital stay than non-dehydrated patients [29]. The inclusion of hip fracture patients may have confounded their analysis, as there is an increasing appreciation for the importance of indication in postsurgical outcomes, especially THA for hip fracture compared to elective THA [30]. Other recent studies using the NSIQP database have implicated longer-term measures of renal function, including estimated glomerular filtration rate (eGFR) as a proposed risk-stratification instrument after primary THA [31]. Similarly, eGFR has also been implicated as a marker for complications after revision TKA [32].

There were several limitations while conducting analysis for this study. To begin with, the reliability of findings obtained from large databases is often called into question. With regards to THAs in particular, a recent study demonstrated that when comparing the National Hospital Discharge Survey (NHDS) database to the Nationwide Inpatient Sample (NIS) database, over half of the factors in demographics, comorbidities, and complications following THA differed significantly between the two databases [33]. Despite this, NSQIP data are chartabstracted and undergo routine auditing, ultimately leading to its acceptance as the standard for database studies [34]. Another limitation to this study is the means by which hydration status was determined. Because the preoperative laboratory tests were often drawn outside of the $24 \mathrm{~h}$ before surgery, there was potential for patients' hydration status to be corrected prior to surgery, and the observed outcomes were due to factors other than dehydration. Additionally, although $\mathrm{BUN} / \mathrm{Cr}$ ratio is a validated metric of volume status in the literature [35], this definition of dehydration status may have contributed to an overestimation of the number of patients who were dehydrated prior to surgery. Finally, though BUN/ $\mathrm{Cr}$ ratio is traditionally used as a marker of dehydration, it may also rise for other reasons. For example, urea may also rise in hypercatabolic states, with an upper gastrointestinal bleeding, and with high-dose glucocorticoid 
Table 4 Relative risk of complications in the 30-day postoperative period for patients undergoing primary total knee arthroplasty

\begin{tabular}{|c|c|c|c|}
\hline Adverse Event & $\mathbf{R R}^{\mathrm{a}}$ & $99.7 \% \mathrm{Cl}$ & $P$-value ${ }^{b}$ \\
\hline Any Complications & 0.97 & $0.92-1.03$ & 0.138 \\
\hline Urinary tract infection & 1.09 & $0.96-1.23$ & 0.040 \\
\hline Blood transfusion & 1.02 & $0.96-1.07$ & 0.408 \\
\hline Extended length of stay ( $>3$ days) & 0.94 & $0.91-0.97$ & $<0.001$ \\
\hline Readmission & 0.91 & $0.86-0.97$ & $<0.001$ \\
\hline Death & 1.00 & $0.72-1.39$ & 0.973 \\
\hline Pneumonia & 0.88 & $0.73-1.07$ & 0.059 \\
\hline Return to the operating room & 0.91 & $0.82-1.01$ & 0.007 \\
\hline Wound complications & 0.98 & $0.88-1.09$ & 0.586 \\
\hline Thromboembolic complications ${ }^{c}$ & 0.99 & $0.90-1.09$ & 0.825 \\
\hline Sepsis/septic shock & 0.92 & $0.74-1.16$ & 0.303 \\
\hline Respiratory complications & 0.91 & $0.68-1.21$ & 0.322 \\
\hline Cardiac complications & 1.00 & $0.81-1.23$ & 0.993 \\
\hline Renal complications & 0.83 & $0.63-1.10$ & 0.047 \\
\hline Stroke/cerebrovascular accident & 1.03 & $0.70-1.51$ & 0.805 \\
\hline
\end{tabular}

a Poisson regressions with robust error variance were used to compare these variables. Adjusted for age, gender, BMl, ASA class, diabetes, and smoking status

${ }^{b}$ Bold fonts indicate statistical significance (significant at $P<0.003$ due to Bonferroni correction for multiple comparisons). RR Relative risk, $\mathrm{Cl}$ Confidence interval (99.70\% Cl due to Bonferroni)

'Includes deep vein thrombosis and pulmonary embolism administration. Additionally, many patients undergoing THA and TKA for osteoarthritis are taking non-steroidal anti-inflammatory (NSAID) medications which can increase BUN and creatinine levels [36]. Because of this, it could be worth examining dehydration in future studies by using alternative metrics such as orthostasis or urine specific gravity.

Despite these limitations, this study of 188,629 patients undergoing THA demonstrated that dehydration status carries no independent risk of any postoperative complications and may correlate with a small but statistically significant reduction in extended length of hospital stay when compared to patients who met laboratory criteria for preoperative hydration. This study also demonstrated similar findings in 332,485 patients undergoing TKA. When laboratory values were limited to only those drawn just before surgery, there was no reduction in risk of extended LOS or readmission and dehydration did not increase risk of complications. Future studies should be conducted to characterize dehydration by alternative metrics that more closely assess hydration status, measuring hydration status at a time closer to surgery, and examining the role of hydration in different orthopedic procedures that may be more sensitive to preoperative hydration status.

\section{Multivariate Odds of Complications after TKA}

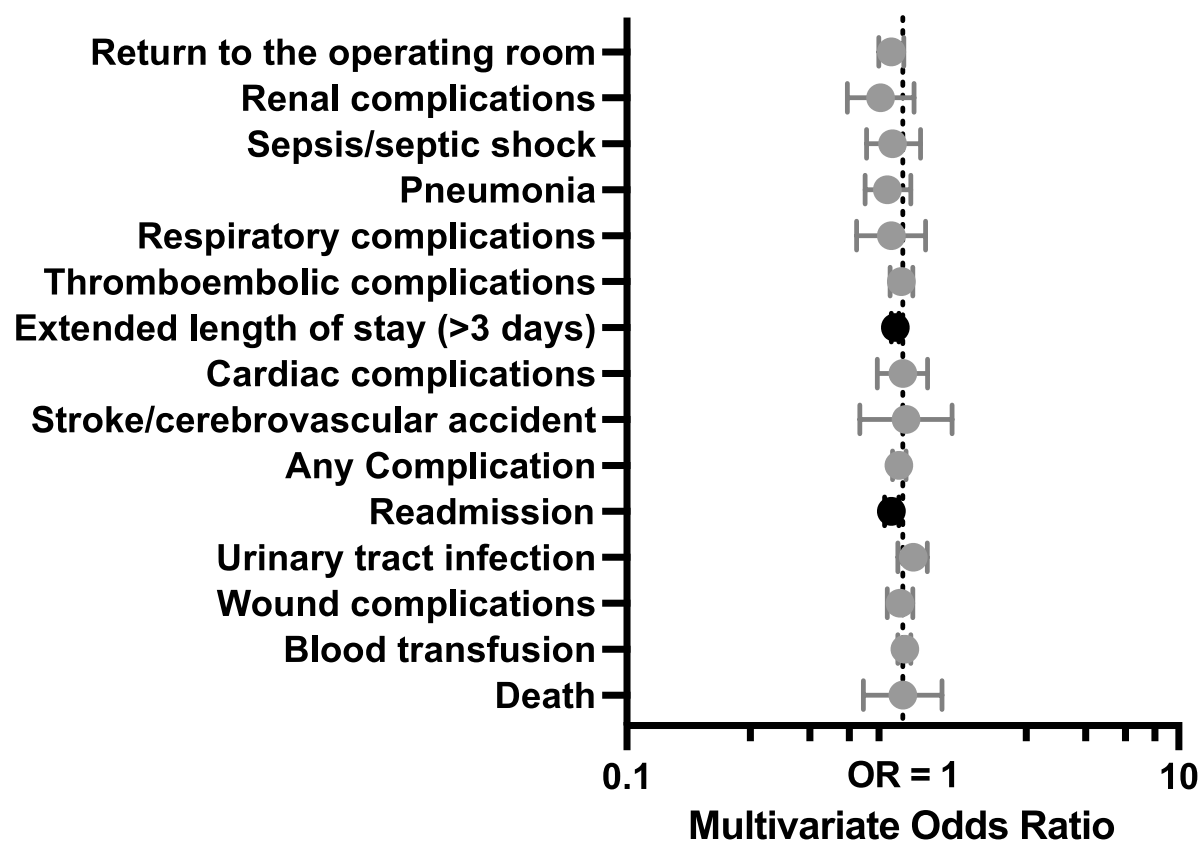

Fig. 3 Relative risk of complications that occurred anytime during the 30-day postoperative period following total knee arthroplasty in non-dehydrated vs. dehydrated patients. Dark shading indicates statistical significance 


\section{Conclusions}

In conclusion, this study found that dehydration was not independently associated with an increase in complications within the 30-day postoperative period after primary total joint arthroplasty, and did not result in an increased risk of blood product transfusion. Accordingly, this study suggests that hydration status, at least determined by the BUN and creatinine ratio, warrants further investigation in assessing a patient's risk of complications and optimizing the postoperative recovery. Ultimately, the findings of this study can help to inform health-care providers on interpreting perioperative hydration indicators and its role in the management of patients to reduce the risk of postoperative complications.

\section{Abbreviations}

NSQIP: National Surgical Quality Improvement Program; THA: Total hip arthroplasty; TKA: Total knee arthroplasty; ASA: American Society of Anesthesiologists; BUN: Blood urea nitrogen (mg/dL); Cr: Creatinine (mg/dL); BMI: Body mass index; CHF: Congestive heart failure.

\section{Supplementary Information}

The online version contains supplementary material available at https://doi. org/10.1186/s42836-021-00090-8.

Additional file 1: Supplemental Table 1. Demographics and comorbidities for patients undergoing primary THA within 24 hours after blood BUN and Creatinine values were collected. Supplemental Table 2 . Relative risk of complications in the 30-day postoperative period for patients undergoing primary THA within 24 hours after blood BUN and Creatinine values were collected. Supplemental Table 3. Demographics and comorbidities for patients undergoing primary TKA within 24 hours after blood BUN and Creatinine values were collected. Supplemental Table 4. Relative risk of complications in the 30-day postoperative period for patients undergoing primary TKA within 24 hours after blood BUN and Creatinine values were collected.

\section{Acknowledgements}

Not Applicable.

\section{Authors' contributions}

HGM, MAJ, LER, JNG all made substantial contribution to design, analysis, interpretation of data, and were major contributors to the writing of the initial and revised manuscript. DSK contributed to the acquisition and interpretation of data. PJB substantially contributed to the writing and editing of the manuscript. All authors read and approved the final manuscript.

\section{Funding}

The research presented has not received any grant funding.

\section{Availability of data and materials}

Data from the National Surgical Quality Improvement Program Participant Use Files for yers 2012-2019 are freely available to participating institutions. The American College of Surgeons National Surgical Quality Improvement Program and the hospitals participating in the ACS NSQIP are the source of the data used herein and they have not verified and are not responsible for the statistical validity of the data analysis or the conclusions derived by the authors.

\section{Declarations}

Ethics approval and consent to participate

No IRB approval is required for the study because the data were deidentified.

\section{Consent for publication}

All authors consent to the publication of this manuscript.

\section{Competing interests}

The authors declare that they have no competing interests and they were not involved in the journal's review of or decisions related to, this manuscript.

\section{Author details}

${ }^{1}$ Weill Cornell Medical College, New York, NY, USA. ${ }^{2}$ Yale School of Medicine, New Haven, CT, USA. ${ }^{3}$ Department of Orthopaedics and Rehabilitation, Yale School of Medicine, 47 College Street, New Haven, CT 06511, USA.

Received: 11 April 2021 Accepted: 5 August 2021

Published online: 04 October 2021

\section{References}

1. Moyer R, Ikert K, Long K, Marsh J. The value of preoperative exercise and education for patients undergoing total hip and knee arthroplasty: a systematic review and meta-analysis. JBJS Rev. 2017;5(12):e2.

2. Abola MV, Tanenbaum JE, Bomberger TT, Knapik DM, Fitzgerald SJ, Wera GD. Preoperative hyponatremia is associated with reoperation and prolonged length of hospital stay following total knee arthroplasty. J Knee Surg. 2019;32(4):344-51.

3. Rao SS, Chaudhry YP, Solano MA, Sterling RS, Oni JK, Khanuja HS. Routine preoperative nutritional screening in all primary total joint arthroplasty patients has little utility. J Arthroplasty. 2020;35(12):3505-11.

4. Peng J, Wu G, Chen J, Chen H. Preoperative C-reactive protein/albumin ratio, a risk factor for postoperative delirium in elderly patients after total joint arthroplasty. J Arthroplasty. 2019;34(11):2601-5.

5. Lu M, Sing DC, Kuo AC, Hansen EN. Preoperative anemia independently predicts 30-day complications after aseptic and septic revision total joint arthroplasty. J Arthroplasty. 2017;32(9s):S197-s201.

6. Renfree SP, Chung AS, Waldrop RA, Crandall D, Chang MS. Preoperative dehydration does not increase the risk of complications following elective lumbar surgery. Spine (Phila Pa 1976). 2019;44(22):E1336-e1341.

7. O'Neill DF, Webb TC. Less is more: limiting narcotic prescription quantities for common orthopedic procedures. Phys Sportsmed. 2014;42(4):100-5.

8. Fawcett WJ, Thomas M. Pre-operative fasting in adults and children: clinical practice and guidelines. Anaesthesia. 2019;74(1):83-8.

9. Ali SZ, Taguchi A, Holtmann B, Kurz A. Effect of supplemental preoperative fluid on postoperative nausea and vomiting. Anaesthesia. 2003;58(8):780-4

10. Yilmaz N, Cekmen N, Bilgin F, Erten E, Ozhan MÖ, Coşar A. Preoperative carbohydrate nutrition reduces postoperative nausea and vomiting compared to preoperative fasting. J Res Med Sci. 2013;18(10):827-32.

11. Gross CR, Lindquist RD, Woolley AC, Granieri R, Allard K, Webster B. Clinical indicators of dehydration severity in elderly patients. J Emerg Med. 1992;10(3):267-74.

12. Chan HYL, Cheng A, Cheung SSS, et al. Association between dehydration on admission and postoperative complications in older persons undergoing orthopaedic surgery. J Clin Nurs. 2018;27(19-20):3679-86.

13. Lacey J, Corbett J, Forni L, et al. A multidisciplinary consensus on dehydration: definitions, diagnostic methods and clinical implications. Ann Med. 2019:51(3-4):232-51.

14. Sloan M, Premkumar A, Sheth NP. Projected Volume of Primary Total Joint Arthroplasty in the U.S., 2014 to 2030. J Bone Joint Surg Am. 2018;100(17):1455-60.

15. Weinberg AD, Minaker KL, Coble YD Jr, et al. Dehydration: evaluation and management in older adults. JAMA. 1995;274(19):1552-6.

16. Bennett JA, Thomas $V$, Riegel B. Unrecognized chronic dehydration in older adults: examining prevalence rate and risk factors. J Gerontol Nurs. 2004;30(11):22-8. quiz 52-23. 
17. Sujino Y, Nakano S, Tanno J, et al. Clinical implications of the blood urea nitrogen/creatinine ratio in heart failure and their association with haemoconcentration. ESC Heart Fail. 2019;6(6):1274-82.

18. Tan WP, Talbott VA, Leong QQ, Isenberg GA, Goldstein SD. American Society of Anesthesiologists class and Charlson's comorbidity index as predictors of postoperative colorectal anastomotic leak: a single-institution experience. J Surg Res. 2013;184(1):115-9.

19. Whitmore RG, Stephen JH, Vernick C, et al. ASA grade and Charlson Comorbidity Index of spinal surgery patients: correlation with complications and societal costs. Spine J. 2014;14(1):31-8.

20. Bahouth MN, Gottesman RF, Szanton SL. Primary 'dehydration' and acute stroke: a systematic research review. J Neurol. 2018;265(10):2167-81.

21. Schrock JW, Glasenapp M, Drogell K. Elevated blood urea nitrogen/creatinine ratio is associated with poor outcome in patients with ischemic stroke. Clin Neurol Neurosurg. 2012;114(7):881-4

22. Ylinenvaara SI, Elisson O, Berg K, Zdolsek JH, Krook H, Hahn RG. Preoperative urine-specific gravity and the incidence of complications after hip fracture surgery: a prospective, observational study. Eur J Anaesthesiol. 2014;31(2):85-90.

23. Wakefield BJ, Mentes J, Holman JE, Culp K. Postadmission dehydration: risk factors, indicators, and outcomes. Rehabil Nurs. 2009;34(5):209-16.

24. Ohkuma T, Nakamura $U$, Iwase $M$, et al. Effects of smoking and its cessation on creatinine- and cystatin C-based estimated glomerular filtration rates and albuminuria in male patients with type 2 diabetes mellitus: the Fukuoka Diabetes Registry. Hypertens Res. 2016;39(10):744-51.

25. Halimi JM, Giraudeau B, Vol S, et al. Effects of current smoking and smoking discontinuation on renal function and proteinuria in the general population. Kidney Int. 2000;58(3):1285-92.

26. Singh JA, Yu S, Chen L, Cleveland JD. Rates of total joint replacement in the United States: future projections to 2020-2040 using the national inpatient sample. J Rheumatol. 2019;46(9):1134-40.

27. Holt JB, Miller BJ, Callaghan JJ, Clark CR, Willenborg MD, Noiseux NO. Minimizing blood transfusion in total hip and knee arthroplasty through a multimodal approach. J Arthroplasty. 2016;31(2):378-82.

28. Fillingham YA, Ramkumar DB, Jevsevar DS, et al. Tranexamic acid in total joint arthroplasty: the endorsed clinical practice guides of the
American Association of Hip and Knee Surgeons, American Society of Regional Anesthesia and Pain Medicine, American Academy of Orthopaedic Surgeons, Hip Society, and Knee Society. Reg Anesth Pain Med. 2019;44(1):7-11.

29. Mukand JA, Cai C, Zielinski A, Danish M, Berman J. The effects of dehydration on rehabilitation outcomes of elderly orthopedic patients. Arch Phys Med Rehabil. 2003;84(1):58-61.

30. Schairer WW, Lane JM, Halsey DA, lorio R, Padgett DE, McLawhorn AS. The Frank Stinchfield Award: total hip arthroplasty for femoral neck fracture is not a typical DRG 470: a propensity-matched cohort study. Clin Orthop Relat Res. 2017;475(2):353-60.

31. Cohen JS, Gu A, Wei C, et al. Preoperative estimated glomerular filtration rate is a marker for postoperative complications following revision total knee arthroplasty. J Arthroplasty. 2019;34(4):750-4.

32. Warren JA, George J, Anis HK, et al. Effects of estimated glomerular filtration rate on 30-day mortality and postoperative complications after total hip arthroplasty: a risk stratification instrument. J Arthroplasty. 2020;35(3):786-93.

33. Bekkers S, Bot AGJ, Makarawung D, Neuhaus V, Ring D. The national hospital discharge survey and nationwide inpatient sample: the databases used affect results in THA research. Clin Orthop Relat Res. 2014;472(11):3441-9.

34. Shiloach M, Frencher SK, Steeger JE, et al. Toward robust information: data quality and inter-rater reliability in the American College of Surgeons National Surgical Quality Improvement Program. J Am Coll Surg. 2010;210(1):6-16.

35. Martinez LC, Khan SF, Bowman BT. Approach to electrolyte abnormalities, prerenal azotemia, and fluid balance. Prim Care. 2020;47(4):555-69.

36. Patel $\mathrm{K}$, Diamantidis $C$, Zhan $M$, et al. Influence of creatinine versus glomerular filtration rate on non-steroidal anti-inflammatory drug prescriptions in chronic kidney disease. Am J Nephrol. 2012;36(1):19-26.

\section{Publisher's Note}

Springer Nature remains neutral with regard to jurisdictional claims in published maps and institutional affiliations.
Ready to submit your research? Choose BMC and benefit from:

- fast, convenient online submission

- thorough peer review by experienced researchers in your field

- rapid publication on acceptance

- support for research data, including large and complex data types

- gold Open Access which fosters wider collaboration and increased citations

- maximum visibility for your research: over $100 \mathrm{M}$ website views per year

At BMC, research is always in progress.

Learn more biomedcentral.com/submissions 